\title{
Maximising the benefits associated with internship learning for undergraduates
}

\section{Christine Fanthome}

Boston University Study Abroad, London, UK

\section{Abstract}

This paper focuses on student responses to an internship programme at an American university in London, with the purpose of highlighting potential areas for curricular improvement. It is based on a survey of 100 undergraduates studying abroad in the UK and concentrates particularly on whether student expectations of their internships are met, the nature of students' perceived personal and professional learning outcomes, and feedback on the current services offered by the internship management team and academic faculty. Findings indicate that student expectations are generally well managed within the current system, and the majority of students feel that their internships have contributed to their personal and professional growth. However, the data highlight discrepancies in the level and nature of support sought by an increasingly diverse student population. Potential improvements are therefore under consideration, such as broader self-help online resources to include video interviews with past students, additional reflective writing workshops, and the establishment of subject linked social media groups for additional peer support.

Keywords: internship; work placement; experiential learning; personal development; learning development; skills development; professional development.

\section{Introduction}

The American university that is the subject of this paper has over thirty years' experience of guiding an increasingly diverse student body through the internship process. Its 
practices and policies are continuously examined critically in the light of student feedback as it seeks to improve its service. This paper will present preliminary findings arising from a new student survey, conducted in autumn 2016, which looks at student expectations and internship experiences in the light of the provision currently offered by the internship managers, some of whom were interviewed for the project. It concludes by making recommendations for additional improvements.

\section{Internships - context and dilemmas}

Student internships have for many decades formed part of the American employment landscape (Benavides et al., 2013). Although the UK is arguably a few years behind the USA in terms of the development of its intern culture (Perlin, 2011; Perlin and Brissenden, 2011), rising undergraduate numbers in Britain within an increasingly competitive job market has meant that, here too, workplace experience on the CV has become a prerequisite to presenting oneself as marketable after graduation (Gault et al., 2010) and securing an advantageous position in terms of job opportunities (Rigsby et al., 2013). Moreover, it is not just employment benefits that are enhanced by an internship experience; there are also academic benefits (Binder et al., 2015). Pizzolato (2008) notes that student learning is enhanced when there is a positive partnership between a student and his/her academic advisor, and Pool and Sewell (2007) identify the advantages to students of receiving guidance, which in turn helps them to develop the key skills they are utilising in the workplace.

Overall, the benefits of work placements are widely acknowledged, most particularly in terms of enhanced employment prospects and personal development opportunities for the student (Fanthome, 2004) and access to a young and vibrant talent pool for the employer (NCUB, 2014). Moreover, reflecting the increasing importance of the global marketplace, there has also been a growth in demand for internships abroad that enable individuals to experience new cultures and develop a global mindset (Gilroy, 2013).

However, despite the known benefits of internship experience, unfortunately the playing field is not level for all students, and there is evidence that certain individuals are at a disadvantage. In the UK, The Sutton Trust (2014) has pointed out that internships are often unpaid and that the participant often needs to live away from home, observing that 
the ability to support oneself with independent funding can therefore be of primary importance. A report commissioned by The Debretts Foundation (2014) reaches similar conclusions, furthermore stating that those without family connections are also disadvantaged. This view is reiterated by Shade and Jacobson (2015) whose research into the experiences of young Canadian women undertaking unpaid internships in the creative sector in Canada and the USA revealed a class-based advantage applicable to those from privileged backgrounds. Similarly, Fisher's (2013) article on White House interns reveals the role of nepotism and networking in the selection process for these positions.

Internship modules within higher education curricula can address these obstacles and offer a solution to these concerns by providing relevant internships within commuting distance of students' term time location, based on individuals' talents and aspirations, regardless of financial or social circumstances, and in addition they are underpinned by a strong advisory support system to ensure that the diverse student body is able to attain academic and personal goals. Although the case study in this paper details the experiences of international students in London, the benefits to students of joining an internship programme undertaken locally near their place of study, and supported by dedicated professional internship managers and academic faculty, would equally apply within the British context of a UK module provided by a UK university for its students.

\section{London internship programme}

Students on the London internship programme come to the UK from the USA for one semester, the first half of which is spent on the university campus studying one core module plus one elective module, with lectures totalling sixteen hours per week. In the second half of the semester, by which time the students are acclimatised to living in London, they intern for four days per week for a period of six weeks in a business related to their major subject studied. On the fifth working day they attend lectures at the university and may, if they wish, take this opportunity to meet with faculty, staff or their internship managers to discuss any aspects of their learning.

However, the process leading up to the start of the internship module begins three to five months before students arrive in the UK. The first meeting between students on the programme and internship managers takes place in the USA. Each student completes an 
online registration form giving details of their resumé, achievements, aims, subjects studied, hobbies and internship goals, two days in advance of being interviewed by an internship manager, when the form is discussed in detail in a one-to-one meeting that lasts at least half an hour. The objective is to determine what the student wants, the areas to which the student might be open, and the areas that are not of interest or unrealistic. Each student is given feedback on his/her resumé together with an opportunity to articulate what they hope to achieve through the internship. Answers generally include: improving soft and hard skills, putting into context what they have learned academically through working, getting a chance to test drive an industry, and gaining office experience. A follow-up email is sent shortly after the meeting that captures what has been discussed and offers the student the opportunity to make changes.

Once they arrive in the UK some months later, the students undertake an orientation programme which includes information and assistance about British workplace culture and a range of lectures and discussions focusing on various aspects of life in Britain, such as UK politics, art and culture, education, and legal regulations, for example with regard to alcohol and drugs. The purpose of the orientation programme is to outline what students might encounter in the world of work, and in doing so to manage their expectations, and to prepare them for any cultural differences, mindful of the relationship between culture shock and lack of preparation (Ineson et al., 2006). With growing numbers of non-American international students participating in the London programme, the orientation workshops serve to inform and prepare all individuals from a range of cultures and native languages for what to expect within a British working environment, thus avoiding some of the adjustment issues and acculturative stresses experienced by international students, such as difficulties with social interaction and emotional reactions to a new environment (Gebhard, 2012), language barriers, interpersonal problems, and daily independent living stressors (Poulakis et al., 2017). During orientation the students are informed about the internship process and its timescales, advised about what to expect from the forthcoming interview with their matched organisation, which they need to pass in order to secure the internship, and reminded that interviews in the UK may be different to those in the USA.

A key feature of BUSAL's internship programme is that a bespoke service is offered to students in that they do not compete with each other for internships. Each individual is guided by an internship manager (IM) towards an appropriate opportunity. One internship manager described this as being akin to 'a dating service' (IM1). The matching service 
involves each student being assigned an internship manager for the whole semester who will provide updates and assistance throughout the process. The internship managers consider what the companies are looking for in terms of experience and preferences within the context of the potential intern's resumé, which might include specific GPA (grade percent average) requirements, language requirements and the individual's stated goals. Each internship manager is well placed to find an appropriate match between students and opportunities on offer, and manages expectations by being transparent about any potential barriers, such as lack of relevant relatable skills or academic experience. The unique consideration of the individual and appropriate placement reflects Hergert's (2009) findings that the value of an internship is enhanced when the experience and the student's academic background are integrated.

Between orientation and the start of the internship, students are invited to voluntary 'confidence workshops' which help prepare for workplace interviews by providing mock interviews. Each session can hold up to 25 students. Drop-in sessions are also available on request and comprise one-to-one meetings between the student and her/his internship manager. A week before the start, the internship managers visit each track of students (for example economics majors) and talk to them about internships in that particular track. This takes place during the first of three workshops run by academic faculty and the purpose is to show that the internship manager's work relates to the academic work. The aim of the three academic faculty workshops, which are track specific and take place at the beginning, middle and end of the programme, is to look at the internship from the perspective of the academic subject from which the work stems and view the internship through a subject specific lens. Students each give a presentation about their industry/organisation and discuss any relevant issues with their peers and the faculty member within the context of their track subject. The academic assessments for the module are this presentation, a paper on a project that has been undertaken at work, and a paper critically assessing the internship experience.

Whilst faculty focus on the academic context, internship managers see their role as offering support, managing expectations and pointing out the transferable nature of the internship experience gained so that students can develop a critical awareness of their learning, some students come to the module with unrealistic expectations of what they will be doing on their internship, most specifically when they do not accept that there may be barriers between what they want and what they will be offered, (for example potential 
journalism interns with an inadequate command of English or students who wish to intern in an investment bank when they do not have relevant mathematical skills to undertake the work). One internship manager confirmed that 'as part of our job we always try to manage expectations as much as we can from the very beginning' (IM3), believing students with a realistic outlook tend to be happier in their work environment.

There is an open door policy at all times and late drop-in sessions so that students can attend after work. There is a formal review two weeks into the internship which is an online process in which students are invited to rate their experience. This is followed up by an email and every student gets a response. Students who are not happy are invited in for a discussion and several students are offered practical advice for specific issues. Throughout the internship, e-mail monitoring takes place to ensure that the internship is running smoothly, and at the end of the semester a summary of the evaluations done by students is put into a report by the internship managers and sent to the university in order to make any necessary changes to enhance the module.

\section{Methodology}

In autumn 2016 a new survey was conducted with the purpose of gathering more detailed qualitative and quantitative information from internship students as part of a review of the programme. The survey, which took the form of two questionnaires, completed before the start and in the final week of the internships, was offered to 106 students, which represented just over half of the student cohort for the autumn semester 2016, across a range of six tracks. A survey was considered to be the optimum method of obtaining the relevant data, mainly because it had the advantage of enabling large numbers of respondents in different locations to become involved (Denscombe, 2007). An additional benefit was that it did not require extensive time or resources to implement (Brown and Dowling, 1998).

The groups were selected randomly by the Director for Academic Affairs and take up was very high: of 106 students, 93 contributed to the first questionnaire, and 90 contributed to the second questionnaire approximately six weeks later. As de Vaus (2002) points out, a research method may be judged by its response rate and in this instance the high rate indicates an appropriate choice of methodology. 
In keeping with Brown and Dowling's (1998) observation that confidentiality and anonymity can encourage participation, the distribution of the questionnaires was administered by colleagues, respondents were not identified, and participation was voluntary. Ethical issues were considered carefully at each stage and ethical approval was granted before the empirical research began.

The first part of the survey in both instances delivered quantitative data relating to what the students perceived to be important about their internship. Students were asked to rank ten factors (for example learning skills, meeting new people, having fun) in order of importance. The same factors were used in both the before and after survey, so that their expectations and the reality of their experiences could be directly compared.

In both the before and after surveys, two open questions then followed, designed to gather qualitative data that would provide further clarity about the nature of students' key thoughts and perceptions, most specifically on their learning and development expectations and their perceived personal and professional learning outcomes. The data was processed using Microsoft Excel. In keeping with Bryman's four stages of qualitative analysis (2008), the data from the open questions was coded and indexed according to patterns and themes. As Bell (2010) notes, coding allows key issues to be clustered, which is a step towards making conclusions. Similarly, Blaxter et al. (2010) observe that as the size of the data set is reduced, this can draw attention to significant pieces of data. Four internship managers were also interviewed with the purpose of drawing on their past interactions with interns and identifying recurring themes.

\section{Presentation and discussion of findings}

\section{Key to survey reference codes}

$\mathrm{S}=$ student

$\mathrm{IM}=$ internship manager

$B=$ before internship start, i.e. data from questionnaire 1

$A=$ after, towards internship end, i.e. data from questionnaire 2

Example: B/S19 refers to a comment from student ref code 19 made before internship start, i.e. data from questionnaire 1. 
Figure 1 compares the students' ranking of ten factors in order of importance before and after their internships. The rankings of the various factors varied widely by student with the result that no factor was on average ranked above four or below seven. However, the pattern of rankings was similar before and after, with students selecting learning about workplace culture and enhancing their CVs as being the most important factors both in the anticipatory phase and afterwards in hindsight. The relation between expectations and experiences demonstrates that the students were realistic about what to expect.

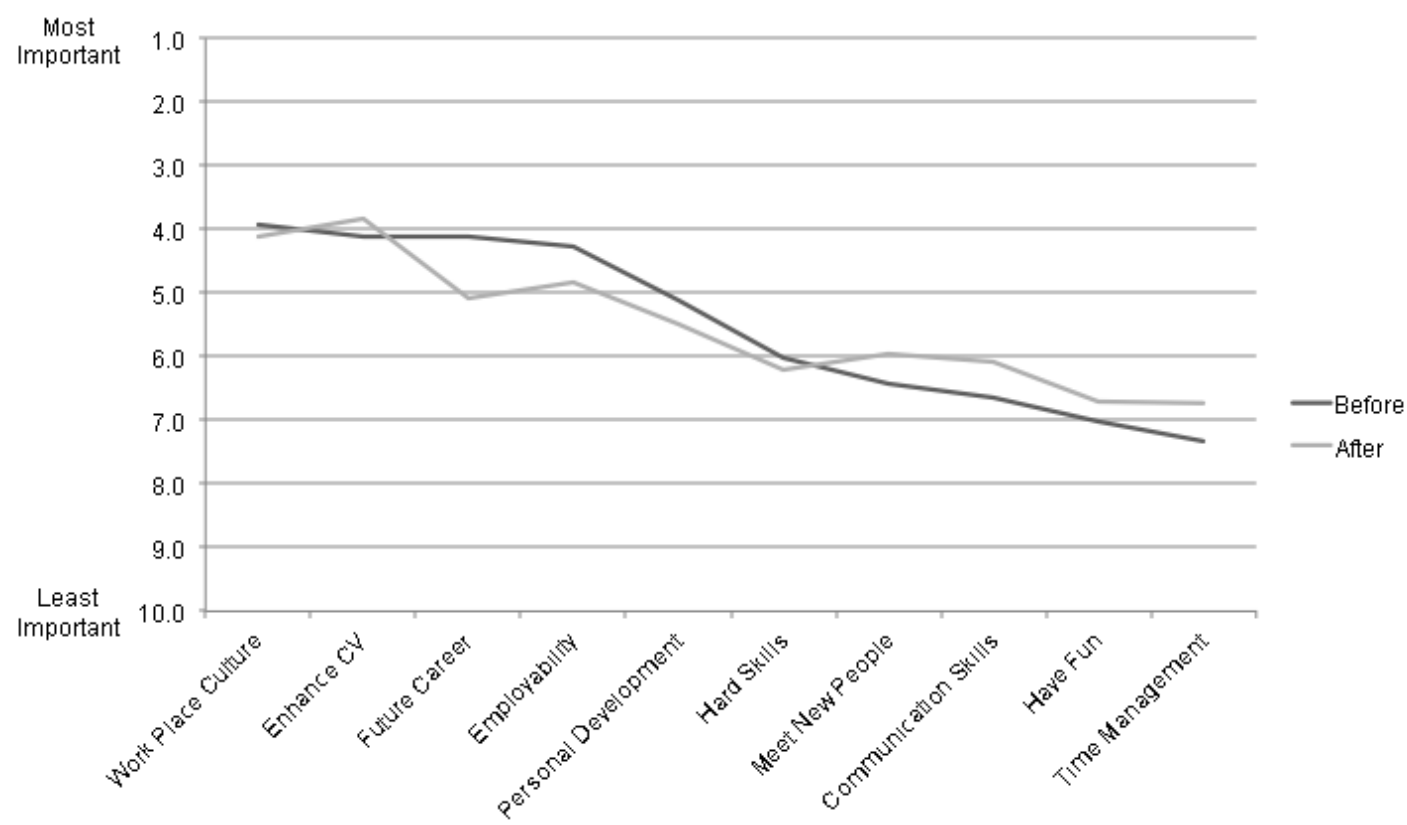

Figure 1. Comparing expectations and experience before and after internship. 93 students ranked 10 expected outcomes of an internship from most to least important before and after their experience. The mean ranking of each outcome is presented above.

\section{Students' anticipatory feelings}

The nature of the students' anticipatory feelings was further explored in the two ensuing open questions. The first asked them to identify what they were feeling as they looked ahead to their internships (Figure 2). It was striking that the word 'excited' occurred frequently in the answers to this question. 58 students used this word (62\%). 53 students $(57 \%)$ identified the opportunity and challenge that they hoped the internship would offer, $20(22 \%)$ mentioned gaining greater industry knowledge and experience, and 20 (22\%) made a firm connection with their future career and employability. The data supported an 
internship manager's comment that: 'They are very keen to have an internship that links to what they hope to do in the future, or what their understanding of what they hope to do in the future is' (IM1).

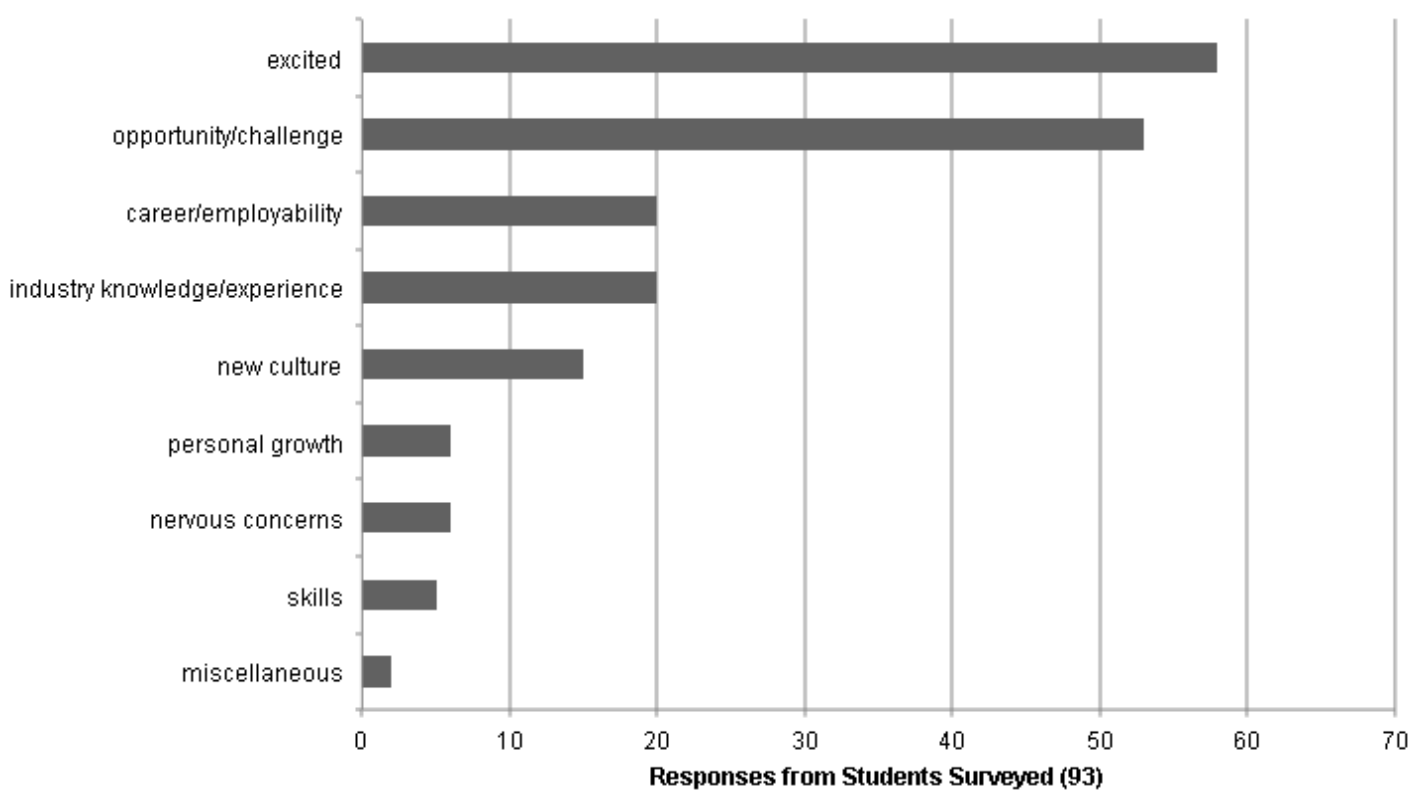

Figure 2. Categorisation of key anticipatory thoughts before internship start.

Students' comments included:

I am excited for the opportunity to work in a British office and learn a new culture. $(\mathrm{B} / \mathrm{S} 45)$

I am excited to start working. I am excited to learn about a new area of my industry that I have never dipped my toes in before. (B/S8)

My main thoughts are that I am excited to be working in this field for the first time. I want to gain more experience in the film/TV industry and I want to experience what it's like to have a job in this field so that I can decide more specifically what l'd like to do as a career. (B/S15)

I am really excited for the internship to begin and can't wait to absorb and contribute as much as I can to the workplace environment. I am excited to learn and challenge myself, while trying my best to make a positive impact. (B/S65) 
The second open question probed specifically about how students thought their internship would contribute to their learning and development. Results showed career issues to be a key preoccupation, mentioned by 40 students (43\%), together with skills, about which 37 students commented (40\%) (Figure 3). However, opportunity/challenge (28 students/30\%), personal growth (24 students/26\%), industry knowledge/experience (19 students/20\%) and new culture (19 students/20\%) were also significant factors.

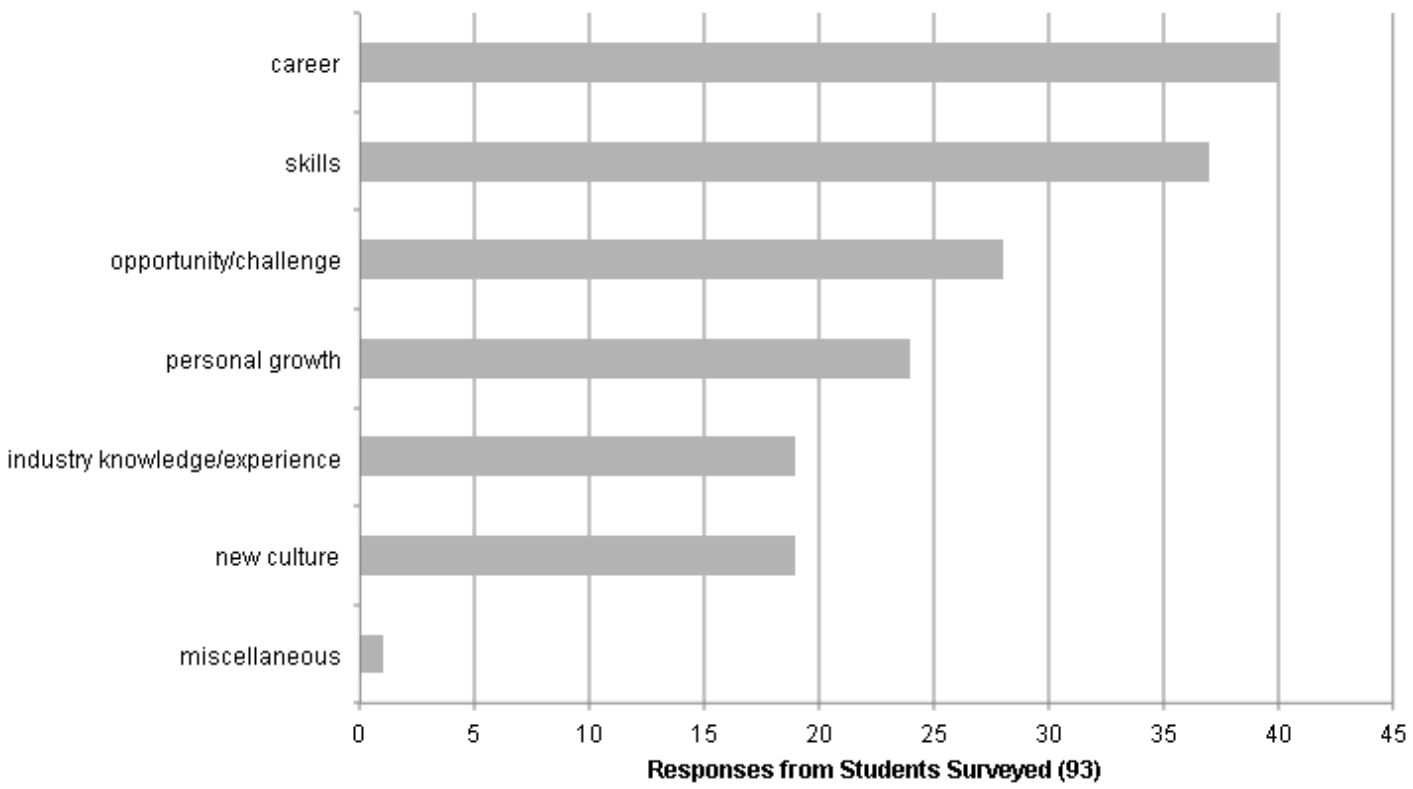

\section{Figure 3. Categorisation of learning and development expectations before internship start.}

Students' comments included:

I think it'll give me more marketable administration skills and experience working in an office. As for real personal growth, I suppose it might help me discover what I want to do re film/TV, but I think I have an OK idea of that already. This is mostly a resume builder. (B/S11)

I think that I'll get better at multi-tasking and handling stress because my internship is supposedly fast-paced and challenging. I hope to get better at prioritizing and decision-making by working in such an environment. (B/S15) 
My internship will push me out of my comfort zone and test my abilities as a future employee, giving me a new understanding of my capabilities. (B/S80)

I think it will help me decide if this is really what I want to do for a career. I think it could give me a network of people that I can use in the future as points of contact. I also think it will push me to be more creative and apply the marketing term. (B/S67)

Internship managers interviewed for this project confirmed that in their experience, students tended to think more about building their resumés rather than considering their personal development. One spoke of students' inclination to focus on 'a big name' for their CV rather than about 'where their skills gaps are' (IM4). This often resulted in a divide between what the student wanted in terms of choice of internship and what the internship manager considered an optimum learning environment for the student. Another noted 'actually what they [students] are probably going to do is find out so much more about themselves personally. I don't know that they always realise that until later' (IM1).

\section{Students' reflections post internship}

Data collected towards the end of the internship period looked at students' perceptions of their personal and professional growth (Figure 4). The great majority of respondents $(78 / 90 \%)$ to this question felt that they had grown as a person and/or that the internship had affected their future decisions. Of the students that indicated they believed their internship had affected their future decisions, most cited the ability to make informed decisions as a key factor (40/44\%). 39 students (43\%) thought that they had grown in terms of greater competence/skills and 23 students (26\%) cited greater understanding. Many expressed increased confidence and self-efficacy, which aligns with Edwards' (2014) findings from a comparable study. For some students, the experience prompted a complete track or career rethink. This is in keeping with Rothman and Sisman's (2016) observations that internships can offer students the chance to learn what they want and what they do not want, thus helping them to define an appropriate career path and avoid the financial and emotional consequences for themselves and their employers of future job dissatisfaction and early turnover. 


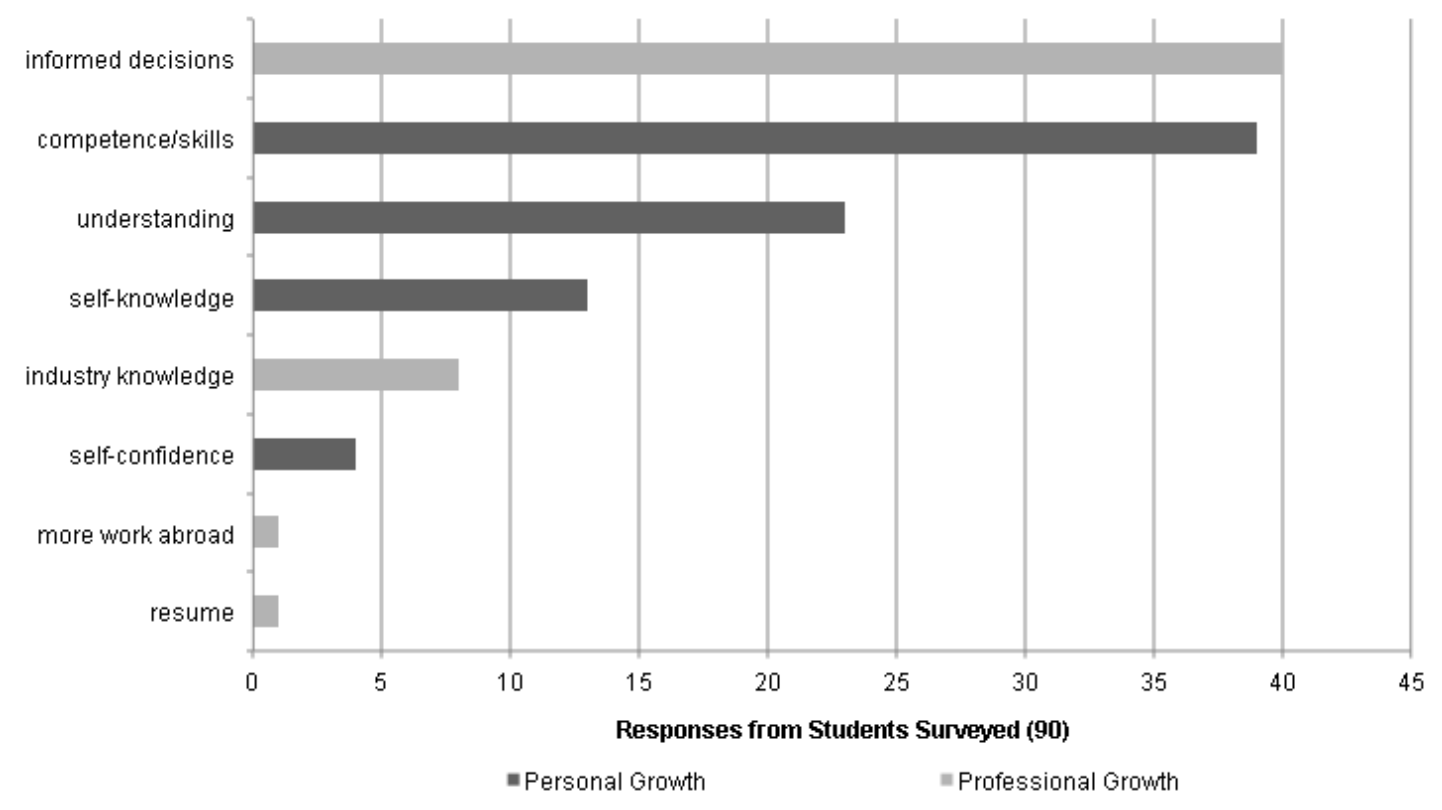

Figure 4. Showing students' perceptions of their learning and development (data collected at end of internship).

Students' comments included:

I developed my oral skills and how I communicate in different environments. (A/S46)

It challenged my professional communication skills a lot and I learned how to work for a boss who can be rude a lot. (A/S15)

Has solidified that I would prefer to work in a larger firm rather than a smaller firm. Taught me the importance of always showing up prepared whether it is for class or work. (A/S71)

My internship solidified my feelings about what I definitely do NOT want to be doing for the rest of my life, and I am now looking into post-graduate opportunities to switch industries entirely. (A/S71)

Since the purpose of the survey was to explore potential enhancements to the curriculum, the final question asked students about the support they had received from internship 
managers and faculty in order to identify opportunities for improvements (Figure 5). Of the responses gathered, 24 students (27\%) wrote mainly positive comments; 35 students (39\%) made fairly neutral statements, 24 students offered critical comments (27\%), and 7 students did not comment. The main areas attracting criticism were lack of communication; lack of choice of internships; a poor fit between the internship and the major subject studied; and lack of advance details. All these criticisms were levelled at the internship management team. Faculty, whose key role was to guide the students through the assessed coursework requirements, were not mentioned in the data apart from in a very few instances in which students were critical of the additional academic workshops scheduled after work when they were already stretched.

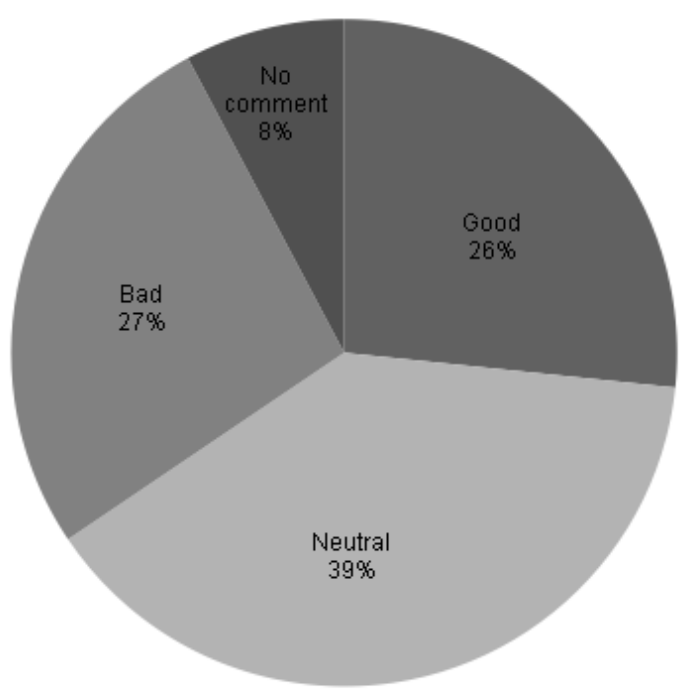

Figure 5. Showing the nature of students' comments about support from staff/faculty (data collected at end of internship).

Students' comments included:

I feel as if they (both teams) did a fine job at communicating with us and supporting us throughout the term. (A/S25)

Honestly, they were great. (A/S19)

They could have communicated more during the placement process - very stressful not knowing what was happening/ if I hadn't spoken up, my interests would not have been catered to. (A/S7) 
Could have given me more timely news on my internship search. When I had questions I had to wait and chase after them. (A/S49)

The issues raised by the students required creative solutions, discussed in the recommendations, because the critical comments from students tended not to offer suggestions for resolving the problems.

\section{Limitations of this study}

Although the take up for this survey was high, not all students chose to respond, and the number of students surveyed (approximately half the autumn cohort for the internship programme from some but not all subject tracks) is relatively small when compared to the yearly intake for this module. Findings may or may not be representative of the full student intake or indeed the cohort of previous or subsequent semesters. Students were not identified by track, so subject specific issues and solutions could not be identified.

\section{Overview and recommendations}

Since data indicates that generally students' expectations were well managed and the majority were satisfied with their internships, the current system requires additions rather than major changes. The orientation programme, in particular, may be considered a success, as culture shock and related issues were avoided.

However, whereas in most literature about internship the student body is considered as a whole, it is clear from this data that the spectrum of required support is great. Whilst some students do not want any further demands on their time, and have indeed commented on the difficulties of combining work with internship seminars, others would welcome further provision.

I also think that we should only have to work 3 days a week if we are required to do this extra seminar work. (A/S21)

More frequent seminar discussions/check-ins [required]. (A/S66) 
Therefore an optimum way forward would be to augment the range of online resources available as these could be accessed on a voluntary self-referral basis. Additional resources might, for example, usefully include information and advice on common problems, along with decision charts indicating the optimum course of action and choices available. Additional information online is an out-of-hours resource and would also ease the frustration felt by some students whilst waiting for an appointment with or response from their internship manager. In this study several students cited lack of communication as an issue. Further investigation revealed that what they meant was that when they emailed their internship manager with a query they expected an immediate response and found the waiting time for an answer problematic, which is in keeping with Pedro's (2006) findings that the everyday lives of millennial students are characterised by instant communication. The internship managers also confirmed that it is an ongoing problem to persuade students to acknowledge that apart from in an emergency situation, the team responds within business hours, as do the organisations accepting students. Average response times could usefully be highlighted clearly as part of the flow charts so that the students could better understand the expected timescale.

Student social media groups arranged by subject track might be considered, as although research has shown that some students can be disadvantaged in social media groups (Garcia et al., 2015) and international students are less likely to disclose their problems via social media sites, (Seo et al., 2016) there is evidence that they can increase peer bonding and act as a resource for communal support (Uusiautti and Määttä, 2014). Social media offers the advantage of a full time presence and would be somewhere for students to turn outside of office hours.

The survey data revealed a wide range in the quality and depth of student comments, with some students clearly being able and motivated to expound their thoughts in some detail and others offering short bullet points with no real explanation. The spectrum of analytical expression might indicate that some students in particular would benefit from guidance in reflective thinking and writing. Lang and McNaught (2013) found that reflective writing workshops enabled students to reach a deeper level of understanding of internship learning. This might also reduce criticism about internship matches by helping students to identify broader learning opportunities inherent in work experience gained outside of one specific career path. This might be a useful addition to the orientation programme. 
Previous students might also be encouraged to contribute to the additional resources site by sharing their perceptions and experiences, possibly in the form of short videos. Gebhard (2012) notes that facilitative behaviours from students experiencing difficulties within a new culture include observation and imitation followed by reflection, so it is likely that some current students would benefit and find reassurance from the insights of previous student cohorts. Another suggestion was to put in place a mentoring system using the social media platform, both for before and after the internship programme.

An augmented website, once constructed, would offer enduring bespoke support for those students who required it. The effectiveness of each aspect of its content would need to be appropriately piloted, assessed and amended for maximum effect.

\section{References}

Bell, J. (2010) Doing your research project: a guide for first-time researchers in education, health and social science. Maidenhead: Open University Press.

Benavides, A., Dicke, L. and Holt, A. (2013) 'Internships adrift: anchoring internship programs in collaboration', Journal of Public Affairs Education, 19(2), pp. 325-353 [Online]. Available at: http://www.jstor.org/stable/23608953 (Accessed: 1 November 2016).

Binder, J., Baguley, T., Crook, C. and Miller, F. (2015) 'The academic value of internships: benefits across disciplines and student backgrounds', Contemporary Educational Psychology, 41(4), pp. 73-82 [Online]. Available at: http://irep.ntu.ac.uk/19477/ (Accessed: 31 October 2016).

Blaxter, L., Hughes, C. and Tight, M. (2010) How to research. $4^{\text {th }}$ edn. Maidenhead: Open University Press.

Brown, A. and Dowling, P. (1998) Doing research/reading research: a mode of interrogation for education. London: Falmer Press.

Bryman, A. (2008) Social research methods. $3^{\text {rd }}$ edn. Oxford: Oxford University Press. 
Denscombe, M. (2007) The good research guide: for small-scale social research projects. $3^{\text {rd }}$ edn. Maidenhead: Open University Press.

de Vaus, D. (2002) Surveys in social research. $5^{\text {th }}$ edn. London: Routledge.

Edwards, M. (2014) 'The impact of placements on students' self-efficacy', Higher Education, Skills and Work-Based Learning, 4(3), pp. 228-241 [Online]. Available at: http://www.emeraldinsight.com/2042-3896.htm (Accessed: 18 May 2016).

Fanthome, C. (2004) Work placements - a survival guide for students. Basingstoke: Palgrave Macmillan.

Fisher, J. (2013) 'Revealed: the insiders whose kids got White House internships', New Republic, 25 September, [Online]. Available at: https://newrepublic.com/article/114844/white-house-internships-go-kids-topdemocrats (Accessed: 24 April 2017).

Garcia, E., Elbeltagi, I., Dungay, K. and Hardaker, G. (2015) 'Student use of Facebook for informal learning and peer support', The International Journal of Information and Learning Technology, 32(5), pp. 286-299 [Online]. Available at: http://www.emeraldinsight.com/doi/abs/10.1108/IJILT-09-2015-0024 (Accessed: 26 April 2017).

Gault, J., Leach, E. and Duey, M. (2010) 'Effects of business internships on job marketability: the employers' perspective', Education \& Training, 52(1), pp. 76-88 [Online]. Available at: http://digitalcommons.wcupa.edu/mark facpub/2 (Accessed: 31 October 2016).

Gebhard, J. (2012) 'International students' adjustment problems and behaviors', Journal of International Students, 2(2), pp. 184-193 [Online]. Available at: https://jistudents.files.wordpress.com/2011/12/10-international-student-adjustmentproblems.pdf (Accessed: 25 April 2017). 
Gilroy, M. (2013) 'Colleges develop internships across majors and borders', Education Digest, 79(5), pp. 30-34 [Online]. Available at:

http://search.proquest.com/openview/5d5bb0751bb5f49cd26f3cbf8b1c05b2/1 ?pqorigsite $=$ gscholar \&cbl=25066 (Accessed: 1 November 2016).

Hergert, M. (2009) 'Student perceptions of the value of internships in business education', American Journal of Business Education, 2(8), pp. 9-14 [Online]. Available at: http://files.eric.ed.gov/fulltext/EJ1052655.pdf (Accessed: 31 October 2016).

Ineson, E., Lyons, A. and Branston, C. (2006) 'Cross cultural change, adjustment and culture shock: UK to USA', Tourism, 54(4), pp. 355-365 [Online]. Available at: https://www.researchgate.net/publication/286499819 Cross cultural change adjus tment and culture shock UK to USA (Accessed: 31 October 2016).

Lang, R. and McNaught, K. (2013) 'Reflective practice in a capstone business internship subject', Journal of International Education in Business, 6(1), pp. 7-21 [Online]. Available at: www.emeraldinsight.com/2046-469X.htm (Accessed: 18 May 2017).

NCUB (National Centre for Universities and Business) (2014) 'What are the benefits of a quality placement?' 3 July, [Online]. Available at: http://www.ncub.co.uk/placements-report/the-benefits-of-a-high-qualityplacement.html (Accessed: 23 April 2017).

Pedro, F. (2006) 'The new millennium learners: challenging our views on ICT and learning', OECD-CERI, May [Online]. Available at: https://www.oecd.org/edu/ceri/38358359.pdf (Accessed: 2 October 2017).

Perlin, R. (2011) Intern nation: how to earn nothing and learn little in the brave new economy. London and New York: Verso.

Perlin, R. and Brissenden, J. (2011) 'Internships: privilege and exploitation', New Left Project, 2 June [Online]. Available at: http://www.newleftproject.org/index.php/site/article comments/privilege and exploit ation (Accessed: 25 April 2017). 
Pizzolato, J. (2008) 'Advisor, teacher, partner: using the learning partnership model to reshape academic advising', About Campus, 13(1), pp. 18-25 [Online]. Available at: http://onlinelibrary.wiley.com/doi/10.1002/abc.243/abstract (Accessed: 31 October 2016).

Pool, L. and Sewell, P. (2007) 'The key to employability: developing a practical model of graduate employability', Education + Training, 49(4), pp. 277-289 [Online]. Available at: http://dx.doi.org/10.1108/00400910710754435 (Accessed: 1 November 2016).

Poulakis, M., Dike, C. and Massa, A. (2017) 'Acculturative stress and adjustment experiences of Greek international students', Journal of International Students, 7(2), pp. 204-228 [Online]. Available at: http://files.eric.ed.gov/fulltext/EJ1129152.pdf (Accessed: 25 April 2017).

Rigsby, J., Addy, N., Herring, C. and Polledo, D. (2013) 'An examination of internships and job opportunities', The Journal of Applied Business Research, 29(4), pp. 1311-1143 [Online]. Available at:

http://www.cluteinstitute.com/ojs/index.php/JABR/article/view/7921 (Accessed: 29 October 2016).

Rothman, M. and Sisman, R. (2016) 'Internship impact on career consideration among business students', Education + Training, 58(9), pp. 1003-1013 [Online]. Available at: http://dx.doi.org/10.1108/ET-04-2015-0027 (Accessed: 25 April 2017).

Seo, H., Harn, R-W., Ebrahim, H. and Aldana, J. (2016) 'International students' social media use and social adjustment', First Monday, 21(11) [Online]. Available at: http://journals.uic.edu/ojs/index.php/fm/article/view/6880/5646 (Accessed: 26 April 2017).

Shade, L. and Jacobson, J. (2015) 'Hungry for the job: gender, unpaid internships, and the creative industries', The Sociological Review, 63(S1), pp. 188-205 [Online]. Available at: http://onlinelibrary.wiley.com/doi/10.1111/1467-954X.12249/abstract (Accessed: 25 April 2017).

The Debretts Foundation (2014) Social mobility (conducted by Opinium), 19 November. 
The Sutton Trust (2014) Internship or Indenture? Research Brief - Edition 2, 12 November [Online]. Available at: http://www.suttontrust.com/researcharchive/internships/ (Accessed: 5 October 2016).

Uusiautti, S. and Määttä, K. (2014) 'I am no longer alone - How do university students perceive the possibilities of social media?', International Journal of Adolescence and Youth, 19(30), pp. 293-305 [Online]. Available at: https://www.ncbi.nlm.nih.gov/pmc/articles/PMC4238292/ (Accessed: 26 April 2017).

\section{Author details}

Dr Christine Fanthome is a Lecturer at Boston University Study Abroad in London. She has recently completed an MA in Academic Practice at City, University of London. 